Nloma 2021, 39(2)

Revista de Psicologia, Ciències de l'Eduació i de l'Esport

ISSN: 1138-3194

Facultat de Psicologia, Ciències de l'Educació i de l'Esport Blanquerna

Universitat Ramon Llull

\title{
Efectos de la musicoterapia como técnica terapéutica a distancia en pacientes oncológicos. Ensayo piloto con un modelo de música de carácter relajante
}

\author{
Marta Casellas ${ }^{1,2}$, Jordi Segura², Clara Andrés², Pere Berbel ${ }^{3}$ \& Yngrid López ${ }^{1,4}$ \\ ${ }^{1}$ Associació Música Difusió (España) \\ ${ }^{2}$ Universitat Ramon Llull (España) \\ ${ }^{3}$ Hospital Universitari Mútua de Terrassa (España) \\ ${ }^{4}$ Residència Sitges Park (España)
}

Received: 2021-2-26

Accepted: 2021-7-21

https://doi.org/10.51698/aloma.2021.39.2.21-34

Efectos de la musicoterapia como técnica terapéutica a distancia en pacientes oncológicos. Ensayo piloto con un modelo de música de carácter relajante

\begin{abstract}
Se conocen poco los efectos terapéuticos que tiene en el estado de ánimo escuchar música con finalidad terapéutica, en pacientes con cáncer. Se presenta un estudio piloto sobre musicoterapia en el que se aplica un protocolo de música de carácter relajante (MCR) a pacientes oncológicos heterogéneos en fase de seguimiento asistencial. El protocolo en intervención se ha aplicado en modalidad telemedicina (tele-health) y se ha comprobado su eficacia terapéutica. La intervención se ha realizado durante la crisis de la COVID-19. El objetivo principal es realizar el diseño definitivo del protocolo para que pueda ser utilizado con estos pacientes o con otros diagnósticos clínicos. Los resultados muestran que la capacidad de relajación mejora y que las respuestas emocionales negativas se alivian. Las respuestas cognitivas sugieren que la escucha musical mejora las emociones y las ideaciones positivas. Se sugiere que el uso del protocolo MCR en pacientes oncológicos puede tener efectos positivos, pues alivia el estado de ánimo negativo, y protege de la depresión o la ansiedad. Se revisa el protocolo, con las propuestas de mejora, y se sugiere ampliar y profundizar en las variables del contexto y del ambiente, así como en los aspectos de relación terapéutica entre el musicoterapeuta, el psicólogo clínico y el paciente.
\end{abstract}

Keywords: musicoterapia; música relajante; telemedicina; relajación; estado de ánimo.

Effects of music therapy as a distance therapeutic technique for cancer patients. Pilot test with a relaxing music model

\begin{abstract}
Little is known about the effects of listening to recorded therapeutic music on the mood of cancer patients. A pilot music therapy study is presented here, in which a relaxing music (RM) protocol was applied to heterogeneous oncology patients in the follow-up care phase. The individual intervention protocol was applied in a Telehealth mode, and its therapeutic efficacy was verified during the health emergency caused by the Covid-19 crisis. The main objective here is to complete the definitive design of the protocol so that it can be used to treat these patients or those with other clinical diagnoses. The results show an improvement in patients' capacity for relaxation and a greater degree of relief from negative emotional responses. The cognitive responses suggest that listening to music facilitates improvements in emotions and positive ideations. It is suggested that the use of the RM protocol in cancer patients may have positive effects by relieving negative moods, and that the protocol may protect against depression and / or anxiety. In this article, the protocol is reviewed and proposals for improvement are offered. It is suggested that future research should take a broader and deeper look at the variables of the patients' context and environment, as well as at aspects of the therapeutic relationship between the music therapist, the clinical psychologist and the patient.
\end{abstract}

Palabras clave: music therapy; relaxing music; Tele-health; relaxation; mood. 


\section{Introducción}

La musicoterapia es el uso de la música con objetivos terapéuticos de restauración, mantenimiento y mejora de la salud, tanto física como mental, dirigida por el musicoterapeuta en un contexto terapéutico (American Music Therapy Association [AMTA], 2019). Esta modalidad terapéutica es un proceso sistemático de intervención en el que el terapeuta ayuda al paciente a promover la mejora de su salud a través de experiencias musicales y las relaciones que se desarrollan entre ellas (Bruscia, 1999). La literatura demuestra que la música, debidamente utilizada, produce efectos positivos, físicos, psicológicos y sociales (Koelsch, 2009). La música personalizada ayuda a estimular o a reducir la activación, a promover la relajación, a aliviar o distraer del dolor y a disminuir la ansiedad y el estrés al reducir el sufrimiento, la angustia o el cansancio (Bradt et al., 2016; Mofredj et al., 2016; Raheem et al., 2015; Tan et al., 2020). También facilita la reducción de las dosis de medicación, pues puede complementar las terapias farmacológicas de aquellos pacientes que, por sus patologías crónicas, están politratados y necesitan limitar la toma de fármacos (sedantes, ansiolíticos); por lo tanto, disminuye la sobrecarga funcional orgánica que representa la metabolización de estos fármacos y contribuye a no sufrir efectos secundarios (Berbel, 2015). Diferentes estudios que integran la neurociencia muestran también las ventajas de la música en la recuperación emocional y su influencia en las respuestas cognitivas y conductuales (Jauset, 2013). Asimismo se ha demostrado su eficacia en trastornos neurológicos o psiquiátricos, pues mejora el bienestar en ámbitos de la vida diaria y laboral (Aalbers et al., 2017; Lin et al., 2011; Raglio et al., 2015).

Hablamos de técnicas musicoterapéuticas activas cuando el paciente participa activamente en la producción de música, y de receptivas cuando escucha música en vivo o grabada (Poch, 1999; Van der Steen et al., 2017; Warth et al., 2014) y pueden complementarse con una comunicación verbal, sin que sea prerrequisito para una intervención terapéutica musical (Warth et al., 2014).

Los estudios muestran que la música provoca efectos positivos en el encéfalo y en la actividad cerebral asociada a las emociones, y un impacto favorable en las funciones cognitivas (Chanda \& Levitin, 2013), y también ayuda a regular las constantes vitales (frecuencia cardíaca, presión arterial, oxigenación) según sea el tipo de música estimulante o relajante (Chanda \& Levitin, 2013; Grocke \& Wigram, 2011; Koelsch, 2018). En este sentido, los diferentes estados de ánimo de la persona influyen en las preferencias musicales y en la escucha de la música. Xue et al. (2018) comprobaron que los participantes con estado de ánimo triste se inclinaban a escuchar música triste (y lenta) y los que tenían tendencia a un estado más alegre preferían escuchar música alegre (y rápida). También, las elecciones musicales son tan coherentes con el estado de ánimo como con la memoria autobiográfica, y los recuerdos sobre experiencias y preferencias musicales deben ser tenidas en cuenta antes de una intervención (Bro et al., 2018). Esas preferencias tienen un papel importante a la hora de buscar los efectos y las reacciones, y es oportuno seleccionar aquella música que evoque emociones positivas, como placer o alegría (Salimpoor et al., 2011; Warth et al., 2014).

En los ámbitos hospitalario, clínico o asistencial, la dimensión emocional debe ser abordada en función de los cuadros clínicos y las necesidades de tratamiento, pues un buen estado de ánimo permite la adherencia y el ajuste a la enfermedad (Nogueda-Orozco et al., 2013). La aparición de ansiedad o las manifestaciones de depresión y las respuestas conductuales a estímulos recibidos pueden provocar un malestar añadido a los síntomas físicos de dolor, malestar o sufrimiento (Hernández et al., 2012), y la presencia de distrés o de trastornos emocionales requiere su detección y abordaje lo antes posible (Cabrera et al., 2015).

La literatura sobre los efectos de la música y su aplicación en ámbitos de la salud aporta pocos estudios que incluyan información primordial sobre el tipo de intervención, la metodología o las actividades (Lee, 2016). Además, en las intervenciones de escucha musical, no queda bien especificada la música utilizada (estilo y género) ni los criterios de selección ni la duración de la audición, que son muy variables en los diferentes ensayos (una media de 37.8 minutos con un rango entre 1 minuto y 180 minutos); ni los dispositivos de música utilizados (Lee, 2016). Conocer tanto esos aspectos como la descripción del marco de intervención, las características clínicas de los pacientes, el tiempo y la frecuencia de su aplicación o los métodos para analizar los resultados permitiría evaluar eficazmente los beneficios potenciales de la musicoterapia (Kamioka et al., 2014; Raglio et al., 2014).

La aplicación de la musicoterapia en oncología se orienta, principalmente, a la dimensión emocional. La emoción es un constructo multifactorial que incide en la dimensión psicológica, social o espiritual de la persona y puede tomarse en sentido positivo o negativo, como trastorno asociado al dolor y al sufrimiento. En el paciente oncológico, el distrés puede interferir en su capacidad para afrontar la enfermedad de manera efectiva, en sus síntomas físicos y en su tratamiento (Martí-Augé et al., 2015a). En nuestro estudio se toma como referencia la clasificación de cuatro tipos de emociones (Sanz, 2001): depresión, ansiedad, hostilidad y alegría. Las dos primeras tienen sentido negativo y se orientan al interior de la persona; la hostilidad, también reacción negativa, se dirige a un objeto externo; y la alegría es una respuesta emocional positiva. La investigación muestra que la musicoterapia se aplica a través de modelos y metodologías diversas, según los objetivos y etapas de aplicación (Martí-Augé et al., 2015a). Giordano et al. (2020) han comprobado que el uso de la música es útil para reducir estados de ansiedad en procesos oncológicos prequirúrgicos. Asimismo, el diagnóstico del cáncer y su gestión suele implicar malestar físico y emocional, y disminuye la calidad de vida 
de los pacientes (Martí-Augé, 2015). Los pacientes que han finalizado el tratamiento activo pueden seguir experimentando malestar físico y emocional, y el seguimiento musicoterapéutico puede mejorar su estado de ánimo y bienestar (Martí-Augé et al., 2015b).

Bradt et al. $(2015,2016)$ han comparado la intervención de escucha de música con y sin intervención terapéutica verbal, y han demostrado que ambas modalidades mejoran el estado de ánimo, la capacidad de relajación o la percepción del dolor y permiten evadirse de las preocupaciones relacionadas con el diagnóstico y el tratamiento. Para realizar una intervención de escucha musical, antes de elegirla, hay que evaluar las preferencias del paciente, especialmente por lo que respecta a la escucha de música grabada sin intervención terapéutica verbal (Bradt et al., 2015, 2016). La intervención debe responder a sus necesidades, ayudarle a adaptarse a las demandas y los cambios corporales, y atender su mundo emocional para controlar sus pensamientos negativos y disfuncionales, y abordar posibles dificultades de comunicación y relación (Martí-Augé et al., 2015c). Además, haber sufrido un diagnóstico de cáncer suele generar preguntas de carácter espiritual y existencial, que suscitan a su vez reacciones emocionales (Arranz et al., 2003). En esas situaciones, las intervenciones de apoyo al paciente requieren una actuación profesional no exclusiva del campo de la psicooncología, también de otros ámbitos y especialidades, como la musicoterapia (Pocino et al., 2007; Yélamos \& Fernández, 2009).

La intervención terapéutica a distancia, la telemedicina, es una estrategia utilizada en psicoterapia y en servicios remotos no clínicos (Glover, 2020). Glover et al. (2017) identifican cuatro tipos de telemedicina: sincrónica, asíncrona (store-and-forward), remote patient monitoring y salud móvil ( $m$-health), en la que se incluye nuestro estudio. Raglio (2020) la propone como instrumento adecuado para aplicar los métodos de musicoterapia, concretamente la escucha musical, aconsejable en épocas de pandemia como la de la COVID-19, y aconseja explorar también metodologías musicoterapéuticas aplicadas a distancia. Como apunta Bradt (2020), las restricciones en el comportamiento individual y psicosocial impuestas por esta crisis sanitaria requieren investigar las consecuencias positivas de este tipo de intervención, y ya ha habido estudios sobre el uso de la música terapéutica en pacientes de cáncer durante el confinamiento (Upadhaya et al., 2020).

Además de dotar al paciente de recursos de respuesta psicológica, la telemedicina puede y debe conseguir que se sienta acompañado por un equipo asistencial, que disponga de una red de apoyo que lo asesore y le dé seguridad (Raglio, 2020). Así, la musicoterapia, poco incluida en las redes de tratamientos, puede atender las necesidades terapéutico-rehabilitadoras. Raglio (2020) propone una intervención de escucha terapéutica musical muy similar a la que presentamos en este estudio, aprovechando las posibilidades de la escucha musical debidamente controlada desde una visión global del paciente como persona. En esta, la tecnología es fundamental, pero también hay que asegurar la comunicación a distancia, manteniendo el vínculo entre paciente y terapeuta (Bradt et al., 2015 Giordano et al., 2020). En efecto, en toda relación terapéutica debe preservarse la alianza terapéutica (Corbella \& Botella, 2003; Corbella, 2019, 2020) y en una relación a distancia, asíncrona, hay que prever qué cambios va a sufrir el vínculo. En la telemedicina esta variable ha sido poco considerada. Según Glover (2020) son escasas las investigaciones sobre la relación terapéutica en $e$ therapy y cita la revisión sistemática de Sucala et al. (2012): de 840 estudios recopilados, solo 11 (1.3\%) lo tratan como tema secundario y apenas seis como tema principal.

Nuestro estudio es una prueba piloto para implementar un protocolo de intervención individual en musicoterapia con pacientes oncológicos heterogéneos que han superado el cáncer y están en seguimiento de atención oncológica, mediante un modelo específico de audición de MCR, siguiendo las premisas de Grocke y Wigram (2011). Se propone comprobar los efectos clínicos de la intervención y definir el protocolo definitivo. La intervención consiste en generar un estímulo para la relajación y mejorar las respuestas del estado de ánimo y de conducta, adaptando el protocolo original para su aplicación en modo de terapia telemedicina (Henry et al., 2016; Glover, 2020; Raglio, 2020). El método consiste en que el paciente realice la escucha de música de manera externa al entorno hospitalario, en línea y sin la interacción directa con el terapeuta.

Así, los objetivos del estudio son los siguientes: 1) comprobar los efectos clínicos del modelo de MCR en las respuestas emocionales de pacientes en seguimiento de atención oncológica; 2) a partir de los resultados y la experiencia en la intervención, introducir las mejoras pertinentes en el protocolo; y 3) comprobar el funcionamiento del método como modalidad de telemedicina, para que pudiera ser aplicado, con las oportunas adaptaciones, a otros perfiles de pacientes en el ámbito de la salud.

\section{Método}

\section{Participantes}

En el estudio piloto participaron, voluntariamente, tres pacientes oncológicos prototípicos o de etiología crónica que habían superado la enfermedad; se encontraban en seguimiento de atención oncológica, y cumplían los siguientes criterios de inclusión: a) ser mayor de edad ( $\geq 18$ años), b) haber superado la enfermedad, o de etiología crónica controlada, en seguimiento de atención oncológica, y c) aceptar participar y firmar la hoja consentimiento informado. Los criterios de exclusión fueron los siguientes: a) paciente con tratamiento paliativo, b) presencia de patología psiquiátrica grave o depresión mayor no controlada, y c) no cumplir con los criterios de inclusión. 


\section{Evaluación y material}

Se utilizó un formulario ad hoc de recogida de datos clínicos y sociodemográficos que incluía las siguientes variables: edad, género, estado civil, país de origen, situación laboral, profesión, estadio del tratamiento, diagnóstico clínico psicológico (depresión), junto con datos sobre el contexto musical y las preferencias musicales de los participantes y de participación previa al estudio en sesiones de musicoterapia, a través del historial musical.

Las variables y los instrumentos de evaluación fueron los siguientes (ver tabla 1):

1. Para evaluar los cambios en los indicadores de ansiedad y depresión se usó la escala Hospital Anxiety and Depression Scale (HADS) (Zigmond \& Snaith, 1983) que evalúa síntomas de ansiedad y depresión en el ámbito hospitalario (López-Roig et al., 2000). Tiene una sensibilidad del $80 \%$ de media en pacientes en atención primaria y servicios hospitalarios, y es apropiada tanto para la práctica asistencial como en investigación clínica (Terol-Cantero et al., 2015). Lobo et al. (2002) y López-Roig et al. (2000) la consideran especialmente útil para detectar diferentes niveles de respuesta emocional y de conducta de ansiedad y depresión en las diferentes etapas o situaciones de la enfermedad en pacientes con diagnóstico de cáncer. Su brevedad y la exclusión de ítems de carácter somático (pérdida del apetito o energía, fatiga insomnio, entre otros) la hace especialmente útil para adaptarse a diferentes contextos de salud y médicos (Terol-Cantero, et al. 2015). Esta escala se administró pre y postsesión.

2. Los cambios de estado de ánimo se evaluaron con la escala de valoración del estado de ánimo (EVEA) (Pino-Sedeño, et al., 2010; Sanz et al. 2014), que mide los estados de ánimo transitorios, en un momento determinado, al escuchar música, durante la imaginación guiada y en la creación de imágenes (Sanz, 2001). Tiene una sensibilidad al cambio del $85 \%$ de media en las subescalas que valoran cuatro estados de ánimo: tristeza-depresión, ansiedad, irahostilidad y alegría (Pino-Sedeño et al., 2010). Esta escala se administró pre y postsesión.

3. Para evaluar la capacidad de relajación se usó el cuestionario valoración del estado de relajación (Berbel \& Casellas, 2018). Se puntúan, en una escala del 1 al 10, donde 1equivale a nada y 10 a mucho. Se compone de los siguientes ítems: 1) ¿Se siente excitado/a, nervioso/a o tenso/a? 2) ¿Ahora está o se siente preocupado/a? y 3) ¿En estos momentos tiene o siente miedo? Este cuestionario se administró pre y postsesión.

4. La autovaloración sobre la propia experiencia se recogió con el cuestionario de valoración de expectativas y beneficios del programa de musicoterapia (Berbel \& Casellas, 2018). Aplicado al final del seguimiento (tercera postsesión), consiste en una escala cualitativa (nada, poco, algo, bastante y mucho) para valorar la experiencia y los aspectos del programa (¿le ha ayudado a relajarse?, ¿le ha gustado el programa?, ¿ha cumplido las expectativas?, valoración sobre las músicas propuestas, sugerencias, ¿recomendaría el programa?).

5. La representación cognitiva de la experiencia se recogió con una pregunta abierta: una vez ha escuchado todas las músicas, cuéntenos qué pensamientos ha tenido durante la escucha (recuerdos, personas, escenas, ilusiones, etc.), planteada al final de cada sesión. Las respuestas fueron grabadas en audio y enviadas en línea.

6. Por vía telefónica, pocos días después de haber concluido la intervención, el psicólogo clínico realizó la evaluación del contexto relacional mediante una breve entrevista de conclusión y despedida, con dos preguntas abiertas: 1) ¿Hizo las actividades acompañado/a por alguna otra persona?, ¿quién?, ¿en qué o cómo le ayuda?; 2) ¿Recomendaría que otras personas las realizaran acompañadas por alguien?, ¿por qué?

Las respuestas a las preguntas abiertas se analizaron mediante la técnica de análisis del contenido cualitativo inductivo (Andreu, 2000; Bardin, 2002), construyendo categorías semánticas. Con la pregunta se reconstruyó la representación del participante sobre su experiencia terapéutica, enfocada como interacción entre el sujeto y las músicas. En esa experiencia, facilitada por la escucha, la persona estableció un vínculo con sus recuerdos, su estado actual y la experiencia vivida. Es una experiencia de carácter social, una presentación anclada en las relaciones vividas y las emociones sentidas, que lo capacitan para interpretar y controlar los fenómenos que le afectan (Jodelet, 1984; Moscovici, 1984).

\section{Diseño y procedimiento}

El modelo de escucha de música de carácter relajante (MCR) con protocolo de intervención fue diseñado por la musicoterapeuta cumpliendo los requisitos éticos y deontológicos recogidos en el informe Belmont (1978). La idoneidad de los objetivos y protocolos fueron aprobados por la Comissió d'Ètica i Recerca de la FPCEE Blanquerna (Universitat Ramon Llull) (junio de 2018). Este modelo de escucha de música de carácter relajante (MCR) se fundamentó en la experiencia clínica, así como en la revisión de investigaciones previas sobre los efectos de la música (Chanda \& Levitin, 2013; Koelsch, 2018; Lee, 2016; Ooishi et al., 2017; Xue et al., 2018) y la aplicación terapéutica en ámbitos de salud, clínicos, hospitalarios y asistenciales (Bradt et al., 2016; Bro et al., 2018; Raheem et al., 2015; Salimpoor et al., 2011; Van der Steen et al., 2017), así como su adecuación a las necesidades de los pacientes (Berbel \& Casellas, 2018; Bradt et al., 2015; Bradt et al., 2016; Martí-Augé et al., 2015; Rossetti et al., 2017; Warth et al., 2014).

En cuanto al contenido, se eligió la escucha de músicas de carácter relajante según los criterios de Grocke y Wigram (2011) de tempo estable; estabilidad 
Tabla 1. Diseño del estudio

\begin{tabular}{l}
\hline Evaluación inicial \\
\hline 1. Consentimiento informado \\
2. Recogida de datos: formulario clínico-sociodemográficos-musicales: \\
historial musical (ad hoc) \\
\hline Intervención musicoterapia (audición musical) \\
\hline Musicoterapia: 30 minutos \\
3 sesiones, una por semana, en un máximo de un mes \\
Evaluación antes y después de cada sesión: \\
3. Escala HADS \\
4. Escala EVEA \\
5. Cuestionario de valoración del estado de relajación (ad hoc) \\
Evaluación después de cada sesión: \\
6. Preguntas abiertas: representación cognitiva surgida durante la \\
intervención (ad hoc) \\
\hline Evaluación final (tercera sesión) \\
\hline 7. Cuestionario de expectativas y beneficios del programa de \\
musicoterapia (ad hoc) \\
\hline Entrevista telefónica \\
\hline 8. Descripción del contexto relacional \\
\hline
\end{tabular}

en dinámicas o cambios graduales de volumen, ritmo, timbre y altura; líneas melódicas predecibles; presencia de estructura y forma; timbres suaves; y, en versión instrumental, no vocal, preferente de tempo lento (6080 pulsaciones por minuto), volumen máximo en 60 dB (Kamioka et al., 2014), que probablemente evocaran emociones positivas como placer o alegría (Salimpoor et al., 2011).

Según el diseño, el modelo MCR incluía ocho músicas de diferente género y estilo, aplicadas de modo personalizado atendiendo a las preferencias musicales en cuanto a género y estilo según el historial musical de cada paciente (Raheem et al., 2015). La intervención constó de las siguientes sesiones: a) tres sesiones de 30 minutos de audición musical una vez por semana a lo largo de un mes (Bradt et al., 2016; Lee, 2016), sin interacción terapéutica verbal durante la sesión (Bradt et al., 2015; Bradt et al., 2016; Warth et al., 2014); y b) sesiones externas al entorno clínico-hospitalario, realizadas en el domicilio del paciente y sin un acompañamiento directo del musicoterapeuta. El paciente eligió el momento y el día de la semana de las tres sesiones, siguiendo criterios personales, para evitar sesgos en las respuestas en el estado de relajación. La tabla 1 muestra el diseño general de la intervención y de la evaluación.

Para diseñar el protocolo MCR se siguieron cuatro pasos:

1. Compendio de más de 400 músicas recopiladas en la experiencia clínica, de diferente género y estilo, de carácter relajante, de diferentes culturas, y en distintas versiones (instrumental, vocal).

2. Preselección de 15 músicas de carácter relajante siguiendo los criterios de Grocke \& Wigram (2011), no vocal, de diferente estilo y género: 5 de bandas sonoras originales (BSO); 3 de música clásica; 1 de música clásica contemporánea (minimalista); 1 de música de sonidos de la naturaleza; 1 de jazz; 4 de música de relajación/meditación.

3. Valoración por grupo de expertos en diferentes áreas (un violinista profesional y musicoterapeuta, dos pianistas profesionales y un psicólogo clínico) de cada una de las 15 piezas musicales preselecciona- das, mediante el cuestionario de valoración de músicas de Tanaka y Nogawa (2015).

4. Selección de 8 piezas musicales como un modelo de músicas de carácter relajante, denominado MCR, siguiendo los criterios de Tanaka y Nogawa (2015) partiendo de los resultados de la valoración de los expertos.

El psicólogo clínico realizó la invitación a participar por vía telefónica, informó del contenido del proyecto, envió la documentación (hoja de consentimiento informado y la hoja de instrucciones básicas) y estuvo a disposición telefónica para responder a las consultas.

En cada sesión se escucharon 6 músicas, en versión instrumental y de carácter relajante, con una duración aproximada de 30 minutos, de manera personalizada: 5 piezas musicales elegidas por la musicoterapeuta de entre las 8 que contiene el protocolo MCR atendiendo a las preferencias musicales individuales y 1 pieza musical propuesta por el paciente que cumpliera las características del estudio, manifestada en el historial musical. El participante era libre de elegir la vía de escucha, auriculares individuales o altavoces (Lee, 2016), cuándo escuchar las músicas, y responder en su momento a los cuestionarios. La escucha se realizó fuera del entorno clínico-hospitalario (propio domicilio debido a las restricciones de confinamiento), sin acompañamiento del musicoterapeuta. El envío de los protocolos de valoración se realizó por correo electrónico y del archivo MCR personalizado para cada paciente a través de la plataforma WeTransfer. La recogida se realizó en línea o por correo postal, a criterio del participante.

\section{Resultados}

Al tratarse de un estudio piloto, de muestra reducida, el análisis de resultados se realizó de manera descriptiva, con carácter clínico.

Los participantes fueron considerados prototípicos; eran tres pacientes oncológicos heterogéneos que habían superado la enfermedad y tenían una etiología crónica controlada, con seguimiento de atención oncológica: un paciente que padecía un cáncer medular de tiroides familiar de etiología crónica, que se encontraba en seguimiento de atención controlada con un tratamiento experimental que le reportó una alta calidad de vida; y dos pacientes con cáncer de mama superado que habían finalizado su tratamiento con seguimiento de atención oncológica. Los tres no presentaban ninguna patología clínica psicológica. Completaron las tres sesiones realizadas a lo largo de un mes, durante tres semanas seguidas. Las características de los datos basales de los participantes se recopilaron una semana antes del inicio del estudio y se muestran en la tabla 2 .

\section{Comparación de las variables de ansiedad y depresión pre y post}

Los resultados obtenidos con la escala HADS se muestran en la figura 1. Al inicio de las sesiones, en la sub- 
Tabla 2. Características basales de los participantes

\begin{tabular}{|c|c|c|c|}
\hline & \multicolumn{2}{|c|}{ Participantes } & \multirow[b]{2}{*}{ n. ${ }^{\circ} 3$} \\
\hline & n. ${ }^{\circ} 1$ & n. ${ }^{\circ} 2$ & \\
\hline Edad (años) & 56 & 54 & 63 \\
\hline Género & hombre & mujer & mujer \\
\hline Estado civil & casado & casada & casada \\
\hline País de origen & España & España & España \\
\hline Nivel educativo & ESO & EGB & EGB \\
\hline Situación laboral & pensionista & pensionista & en paro \\
\hline $\begin{array}{l}\text { Estadio del } \\
\text { tratamiento }\end{array}$ & $\begin{array}{l}\text { etiología crónica. } \\
\text { Plan de atención } \\
\text { de seguimiento }\end{array}$ & $\begin{array}{l}\text { cáncer de mama. } \\
\text { Plan de atención } \\
\text { de seguimiento }\end{array}$ & $\begin{array}{l}\text { cáncer de mama. } \\
\text { Plan de atención } \\
\text { de seguimiento }\end{array}$ \\
\hline $\begin{array}{l}\text { Patología clínica- } \\
\text { psicológica }\end{array}$ & NO & NO & $\mathrm{NO}$ \\
\hline $\begin{array}{l}\text { Conocimientos } \\
\text { musicales }\end{array}$ & Sí & Sí & Sí \\
\hline $\begin{array}{l}\text { Participación previa } \\
\text { a la musicoterapia }\end{array}$ & NO & NO & NO \\
\hline
\end{tabular}

escala de ansiedad los participantes $n .^{\circ} 1$ y 2 registraron unos niveles de ansiedad dentro de la normalidad y el n. 3 registró un grado de ansiedad moderado. Comparando los resultados pre y post de cada sesión, los tres mostraron una mayor reducción en la subescala de ansiedad. En la subescala de depresión, al inicio de las sesiones expresaron niveles de depresión no patológicos. Comparando los resultados pre y post, los participantes n. ${ }^{\circ} 1$ y 2 mantuvieron los niveles de depresión, dentro de la normalidad, no patológicos y el participante $n .^{\circ} 3$ registró un aumento en las puntuaciones que indicarían un posible grado de depresión moderado.
HADS PRE y POSTSESIÓN

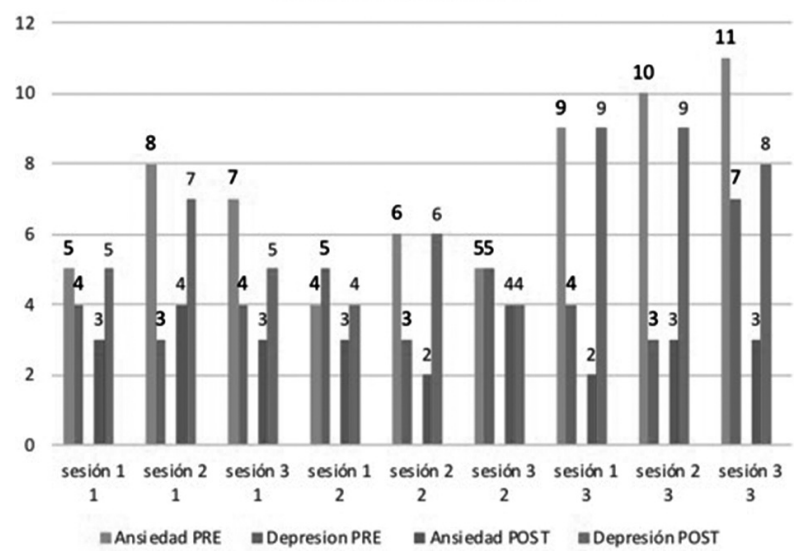

Figura 1. Puntuaciones HADS pre y post

Valoración: rango de puntuación de 0-21 para cada subescala de ansiedad y depresión. Se considera, en cada una de las escalas, que entre 0-7 indica normalidad, entre 8-10 indica nivel moderado, y puntuaciones superiores a 11 son, probablemente, indicación de nivel patológico.

\section{Comparación de las variables de estado de ánimo pre y post}

Los resultados obtenidos con la escala EVEA se muestran en la tabla 2. La comparación antes y después de cada sesión mostraron diferencias, con una reducción de las puntuaciones en las subescalas de afectación negativa (tristeza-depresión, ansiedad e ira-hostilidad), y una puntuación similar o mayor en la subescala de afectación positiva (alegría). En la subescala de ansiedad, presentaron una reducción de las puntuaciones en cada uno de los niveles-componentes de nerviosismo, tensión, ansiedad e intranquilidad.

Tabla 3. Comparación de las variables de estado de ánimo pre y post-sesión (escala EVEA)

\begin{tabular}{|c|c|c|c|c|c|c|c|c|c|c|c|c|c|c|c|c|c|c|}
\hline \multirow{4}{*}{$\begin{array}{l}\text { Participantes } \\
\text { Sesiones }\end{array}$} & \multicolumn{18}{|c|}{ Tipo de tratamiento: audición musical (MCR) } \\
\hline & \multicolumn{9}{|c|}{ PRE } & \multicolumn{9}{|c|}{ POST } \\
\hline & \multicolumn{3}{|c|}{ n. ${ }^{\circ} 1$} & \multicolumn{3}{|c|}{ n. ${ }^{\circ} 2$} & \multicolumn{3}{|c|}{ n. ${ }^{\circ} 3$} & \multicolumn{3}{|c|}{ n..$^{\circ} 1$} & \multicolumn{3}{|c|}{ n. ${ }^{\circ} 2$} & \multicolumn{3}{|c|}{ n. ${ }^{\circ} 3$} \\
\hline & 1 & 2 & 3 & 1 & 2 & 3 & 1 & 2 & 3 & 1 & 2 & 3 & 1 & 2 & 3 & 1 & 2 & 3 \\
\hline Tristeza-depresión & 2.75 & 2.50 & 2.25 & 0.00 & 2.50 & 2.50 & 1.00 & 0.50 & 2.00 & 3.50 & 2.00 & $1.75^{*}$ & 0.00 & $1.00^{*}$ & $2.00^{*}$ & 1.75 & 0.25 & $0.25^{*}$ \\
\hline 4 Melancólico & 3 & 5 & 3 & 0 & 3 & 0 & 1 & 1 & 2 & 6 & 5 & 5 & 0 & 4 & 1 & 1 & 1 & 0 \\
\hline 7 Alicaído & 2 & 2 & 1 & 0 & 4 & 2 & 1 & 1 & 2 & 3 & 1 & 2 & 0 & 0 & 4 & 0 & 0 & 1 \\
\hline 16 Triste & 2 & 1 & 2 & 0 & 1 & 2 & 1 & 1 & 2 & 3 & 1 & 0 & 0 & 0 & 0 & 6 & 0 & 0 \\
\hline 10 Apagado & 4 & 2 & 3 & 0 & 2 & 6 & 1 & 1 & 2 & 2 & 1 & 0 & 0 & 0 & 3 & 0 & 0 & 0 \\
\hline Ansiedad & 5.75 & 3.75 & 3.75 & 3.00 & 2.75 & 1.50 & 1.75 & 1.75 & 3.00 & 3.25 & 1.25 & $1.25^{*}$ & 1.75 & 0.75 & $4.75^{*}$ & 1.25 & 0.75 & $0.00^{*}$ \\
\hline 1 Nervioso & 7 & 4 & 3 & 1 & 4 & 1 & 4 & 3 & 6 & 4 & 1 & 1 & 1 & 1 & 3 & 2 & 2 & 0 \\
\hline 5 Tenso & 1 & 3 & 2 & 3 & 4 & 3 & 1 & 1 & 2 & 2 & 2 & 2 & 0 & 0 & 6 & 1 & 1 & 0 \\
\hline 9 Ansioso & 8 & 5 & 5 & 6 & 1 & 0 & 1 & 1 & 3 & 4 & 1 & 1 & 0 & 0 & 4 & 1 & 0 & 0 \\
\hline 13 Intranquilo & 7 & 3 & 3 & 2 & 2 & 2 & 1 & 2 & 1 & 3 & 1 & 1 & 6 & 2 & 6 & 1 & 0 & 0 \\
\hline Alegría & 6.00 & 6.25 & 6.00 & 5.75 & 6.00 & 3.00 & 5.75 & 4.50 & 2.75 & 6.25 & 6.00 & $6.00^{*}$ & 5.50 & 5.00 & $4.00^{*}$ & 2.75 & 3.25 & $7.50^{*}$ \\
\hline 15 Contento & 6 & 6 & 7 & 9 & 7 & 3 & 5 & 5 & 5 & 6 & 6 & 7 & 6 & 6 & 2 & 0 & 6 & 8 \\
\hline 12 Jovial & 5 & 5 & 6 & 4 & 5 & 0 & 3 & 4 & 2 & 5 & 5 & 5 & 6 & 3 & 3 & 5 & 1 & 6 \\
\hline 13 Alegre & 7 & 7 & 5 & 6 & 7 & 6 & 8 & 5 & 3 & 7 & 7 & 6 & 6 & 6 & 1 & 5 & 5 & 8 \\
\hline 6 Optimista & 6 & 7 & 6 & 2 & 5 & 3 & 7 & 4 & 3 & 7 & 6 & 6 & 4 & 5 & 2 & 1 & 1 & 8 \\
\hline Ira-hostilidad & 2.00 & 2.00 & 1.25 & 0.00 & 1.75 & 0.00 & 1.00 & 0.50 & 2.75 & 0.75 & 0.75 & 0.50 & 0.00 & 0.00 & 0.75 & 0.25 & 0.25 & 0.00 \\
\hline 14 Enfadado & 1 & 2 & 1 & 0 & 0 & 0. & 1 & 1 & 3 & 0 & 1 & 1 & 0 & 0 & 0 & 0 & 0 & 0 \\
\hline 8 Enojado & 2 & 2 & 1 & 0 & 2 & 0 & 2 & 0 & 2 & 0 & 0 & 0 & 0 & 0 & 0 & 1 & 1 & 0 \\
\hline 2 Irritado & 3 & 2 & 2 & 0 & 2 & 0 & 0 & 1 & 4 & 3 & 1 & 1 & 0 & 0 & 3 & 0 & 0 & 0 \\
\hline 11 Molesto & 2 & 2 & 1 & 0 & 3 & 0 & 1 & 0 & 2 & 0 & 1 & 0 & 0 & 0 & 0 & 0 & 0 & 0 \\
\hline
\end{tabular}

Nota: Puntuación: Likert de 0 a 10 para cada variable de cada factor tristeza-depresión, ansiedad, alegría e ira-hostilidad; Punto de corte: 5 


\section{ESTADO RELAJACIÓN PRESESIÓN}

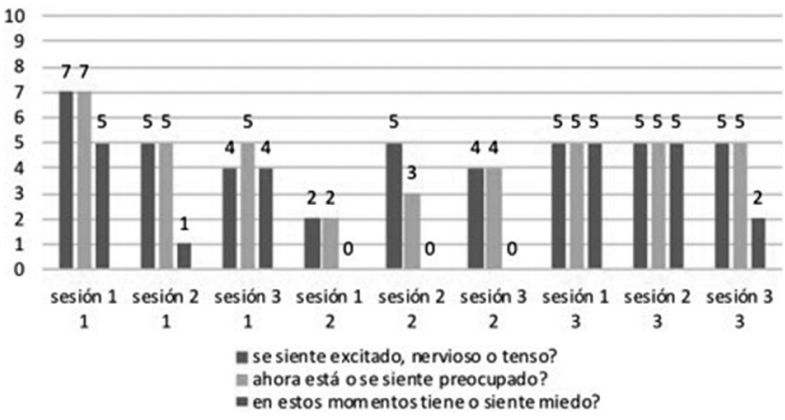

Figura 2. Estado de relación pre-sesión

ESTADO RELAJACIÓN POSTSESIÓN

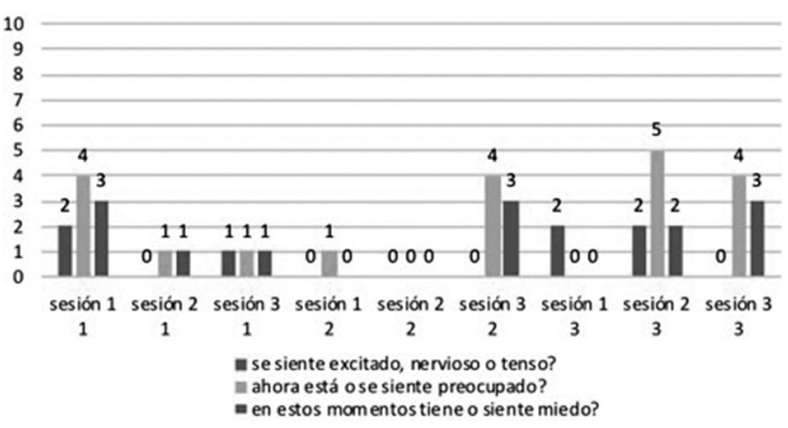

Figura 2. Puntuaciones HADS pre y post

Valoración: rango de puntuación Likert de 0 a 10, de menor a mayor intensidad, para cada variable en las subescalas de tristeza-depresión, ansiedad, alegría e ira-hostilidad, y el punto de corte: 5 .

\section{Comparación de las respuestas del estado de relajación pre y post (Berbel \& Casellas, 2018).}

Comparando los resultados pre y post de cada sesión, se observó una diminución de las puntuaciones al final de cada sesión, con una reducción manifiesta en todas las respuestasa las preguntas: ¿ahora está o se siente preocupado?, ¿en estos momentos tiene o siente miedo?, ¿se siente excitado, nervioso o tenso? Los resultados se presentan en las figuras 2 y 3 .

Las respuestas abiertas dadas al cuestionario de valoración de expectativas y beneficios del programa de musicoterapia (Berbel \& Casellas, 2018) y sobre la representación cognitiva de la experiencia se analizaron las respuestas individuales, después se hizo una clasificación categorial conjunta y, finalmente, una descripción individual, según la metodología propuesta por Andreu (2000) y Bardin (2002).

La valoración de expectativas y beneficios del programa de musicoterapia procedía de 1) responder y dar la opinión sobre la experiencia a partir de sus expectativas, y 2) proponer sugerencias, recomendaciones al programa, una vez finalizadas las tres sesiones. Los tres participantes coincidieron en su satisfacción sobre la experiencia y práctica individual, así como, sobre las músicas propuestas: muy positivas, sencillas, sin demasiado ritmo, que ayudaban a interiorizar. El participante $n .^{\circ} 1$ sugirió añadir nuevas músicas en diferentes sesiones, y el participante $n$. $^{\circ} 2$ prefirió escuchar las elegidas personalmente. Consideraron el programa recomendable. En la tabla 4 se recogen las respuestas.
Tabla 4. Valoración de expectativas y beneficios de la intervención en musicoterapia

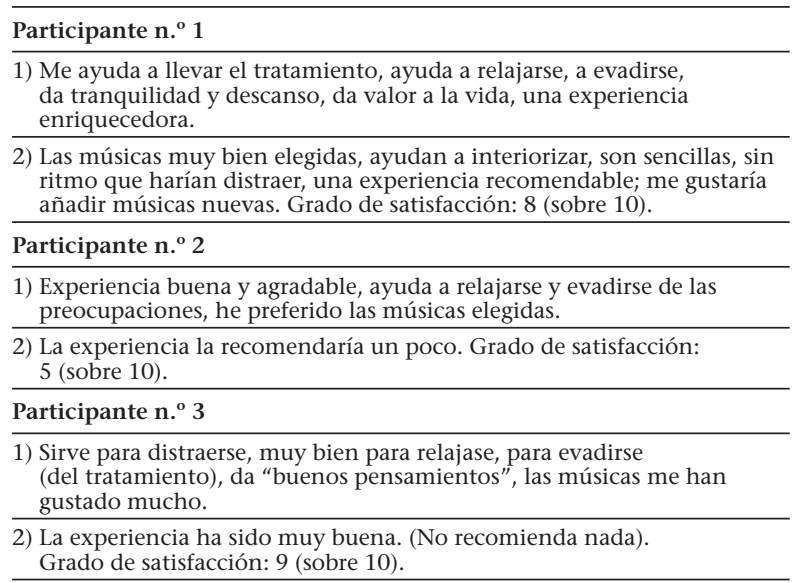

Las respuestas del análisis conjunto de las categorías cognitivas se clasificaron en seis categorías: sensación y expresión emocional, cognitivas (ideación de conductas y sensaciones), ideación de objetos naturales, cualidad interna (subjetiva), actitud existencial y posición existencial (tabla 5). Se cita cada categoría, incluyendo en cada una las expresiones categoriales identificadas. En estas se observó que los contenidos más abundantes, en negrita y en mayúscula, coincidían en la expresión de emociones y sensaciones positivas, y cuando estas eran negativas (miedo, oscuridad), los participantes identificaron rápidamente recursos cognitivos para superarlas.

Tabla 5. Categorías cognitivas

\begin{tabular}{|c|c|c|}
\hline $\begin{array}{l}\text { Sensación y expresión } \\
\text { emocional }\end{array}$ & $\begin{array}{l}\text { Cognitivas: ideación } \\
\text { de conductas y } \\
\text { sensaciones }\end{array}$ & $\begin{array}{l}\text { Ideación de objetos } \\
\text { naturales }\end{array}$ \\
\hline $\begin{array}{l}\text { Tranquilidad } \\
\text { Sensación positiva } \\
\text { Sentimientos buenos } \\
\text { Miedo } \\
\text { Alegría } \\
\text { Paz en el corazón } \\
\text { Gozo (por el entorno) } \\
\text { Llorar (de relajación) }\end{array}$ & $\begin{array}{l}\text { Bailar } \\
\text { Hacer siluetas con las } \\
\text { manos } \\
\text { Sentir olores suaves, } \\
\text { agradables } \\
\text { Observar el interior del } \\
\text { hospital) } \\
\text { Pandemia (observar } \\
\text { pacientes) } \\
\text { Enfermedad } \\
\text { Observar (el entorno) } \\
\text { Observarse a uno } \\
\text { mismo: } \\
\text { Sentado } \\
\text { Tumbado } \\
\text { Caminando } \\
\text { En la cima } \\
\text { Con ganas de bailar }\end{array}$ & $\begin{array}{l}\text { Flores, amapolas } \\
\text { Montaña } \\
\text { Mar } \\
\text { Lluvia } \\
\text { Árboles, paisaje, campo } \\
\text { de trigo } \\
\text { Pajarillos, nidos, piando } \\
\text { Camino (estrecho, } \\
\text { oscuro) } \\
\text { Pasillo de hospital, } \\
\text { baldosas } \\
\text { Quimioterapia } \\
\text { Gotitas de agua por } \\
\text { cristales, balcón } \\
\text { Salida del sol, amanecer } \\
\text { Sol brillante, la tarde } \\
\text { Sonrisa de un niño } \\
\text { Comida (de la mamá) } \\
\text { Metáfora: "después de la } \\
\text { tormenta / esperanza / } \\
\text { futuro" }\end{array}$ \\
\hline $\begin{array}{l}\text { Cualidad interna } \\
\text { (subjetiva) }\end{array}$ & Actitud existencial & Posición existencial \\
\hline $\begin{array}{l}\text { Expansión } \\
\text { Bienestar } \\
\text { Simplicidad } \\
\text { Amplitud } \\
\text { Bondad } \\
\text { Grandeza } \\
\text { Amistad } \\
\text { Amor (a los otros) }\end{array}$ & $\begin{array}{l}\text { Olvido de } \\
\text { preocupaciones } \\
\text { cotidianas } \\
\text { Recuerdos } \\
\text { Dejarme llevar } \\
\text { Espera } \\
\text { Reflexión (sobre la } \\
\text { propia vida) }\end{array}$ & $\begin{array}{l}\text { Propia vida (repaso, } \\
\text { reflexión de historia } \\
\text { personal) } \\
\text { Pasado / presente / } \\
\text { futuro } \\
\text { PASADO: } \\
\text { Infancia feliz } \\
\text { Camino estrecho, } \\
\text { oscuro } \\
\text { Agradecimiento, } \\
\text { gratitud } \\
\text { Otros: } \\
\text { Muerte (de la madre) } \\
\text { Esposo } \\
\text { Hijos, nietos, familia, } \\
\text { seres queridos } \\
\text { Dios: confianza }\end{array}$ \\
\hline
\end{tabular}


En la tabla 6 se hace una descripción diacrónica de las categorías predominantes en cada participante, a lo largo de las tres sesiones, con un resumen-valoración final. El desarrollo de las tres sesiones fue positivo en los participantes n. ${ }^{\circ} 1$ y 3 . La primera sesión del participante $n .^{\circ} 1$ se caracterizó por experimentar emociones y cualidades internas positivas, y aunque la segunda sesión se vio afectada por un control hospitalario que le suscitó emociones negativas, en la misma sesión compensó con reacciones positivas, que mejoraron aún más en la tercera sesión. En el participante n. ${ }^{\circ} 3$ se observó nítidamente el progreso entre sesiones; la estructura de respuestas fue similar en las dos primeras: postura corporal, cualidades positivas, imágenes naturales, agradables y expansivas; en la segunda sesión introdujo el movimiento corporal; y en la tercera se consolidaron los contenidos anteriores. El participante n. ${ }^{\circ} 2$ pareció experimentar ciertas dificultades para seguir el protocolo, al responder solamente al finalizar la tercera sesión, brevemente, manifestando cualidades internas e ideación.

Tabla 6. Contenido cognitivo de cada participante

\begin{tabular}{|c|}
\hline.$^{\circ} 1$ \\
\hline $\begin{array}{l}\text { timera sesión: expresión de emoción positiva de llorar, cualidades } \\
\text { ternas (amplitud, bienestar, simplicidad, sencillez). }\end{array}$ \\
\hline $\begin{array}{l}\text { egunda sesión: "he visto la situación de pandemia (en el hospital)": } \\
\text { xpresa emociones (miedo, incerteza...), seguidas de reacciones } \\
\text { kistenciales compensatorias: ver "todo lo recibido en la vida, de Dios, el } \\
\text { nor de otros, la grandeza de todo. Respuesta de agradecimiento. }\end{array}$ \\
\hline $\begin{array}{l}\text { ercera sesión: aumenta el contenido cognitivo/ideativo sumado a } \\
\text { mociones positivas; "me vienen imágenes a la mente": cima de montaña, } \\
\text { o estaba allí, sin vértigo ni miedo, un pasillo largo y ancho (del hospital); } \\
\text { anquilidad, sin miedo, gratitud, tranquilidad. }\end{array}$ \\
\hline $\begin{array}{l}\text { esumen. En la primera sesión, el paciente está dominado por emociones } \\
\text { cualidades internas positivas. En la segunda semana, el paciente hace } \\
\text { na visita al hospital, que repercute en su actividad: expresa emociones } \\
\text { egativas, que, con la actividad, compensa intensamente (grandeza, lo } \\
\text { cibido de otros, agradecimiento). En la tercera sesión, el paciente } \\
\text { cluye ideación imaginativa, sumada a la emocionalidad positiva y } \\
\text { lantiene las respuestas actitudinales positivas. }\end{array}$ \\
\hline Participante $n .^{\circ} 2$ \\
\hline a paciente solo responde a las preguntas al finalizar la tercera sesión. \\
\hline $\begin{array}{l}\text { De tipo emocional, solo expresión de "haber sentido alegría". Respuestas } \\
\text { eferidas a cualidades internas: "en el momento de escuchar... tenía } \\
\text { entimientos buenos y bastante paz... dejarme llevar... También, } \\
\text { ogniciones: por unos instantes te olvidas de preocupaciones cotidianas... } \\
\text { ambién, algún recuerdo del pasado". }\end{array}$ \\
\hline $\begin{array}{l}\text { aciones y se resiste a } \\
n \text { expresividad emocional y } \\
\text { ternas e ideación. No se }\end{array}$ \\
\hline Participante n. $^{\circ} 3$ \\
\hline $\begin{array}{l}\text { Primera sesión: inicia con una imaginación de su postura corporal y de } \\
\text { objetos naturales (árbol, paisaje...). Añade respuestas de cualidad } \\
\text { positivas: paz, tranquilidad. Continúa con metáforas existenciales: } \\
\text { metáfora de la tormenta superada (esperanza), superar las dificultades del } \\
\text { pasado (quimioterapia), el presente (camino hacia el futuro, sol brillante, } \\
\text { confianza en Dios, nacer del nuevo día), naturaleza, trigo y amapolas. Paz } \\
\text { nterior. }\end{array}$ \\
\hline $\begin{array}{l}\text { gunda sesión: de nuevo inicia con una imaginación de su postura } \\
\text { rporal y la naturaleza: tumbada bajo un árbol, el verano, los pájaros, el } \\
\text { do... (Imagen regresiva: “esperar la comida de mamá”). Añade } \\
\text { ovimiento corporal de sí mima (bailar, gestos manuales...) y más } \\
\text { pansión ideativa: día de lluvia, contemplación con sensibilidad (olores } \\
\text { radables, suaves flores, bonita salida del sol al amanecer). }\end{array}$ \\
\hline $\begin{array}{l}\text { rcera sesión: mayor intensidad de contenido existencial: descanso de los } \\
\text { oblemas, libertad, reflexión (positiva) sobre la propia historia (recuerdos } \\
\text { sitivos, agradecimiento), "paz en el corazón". }\end{array}$ \\
\hline $\begin{array}{l}\text { Resumen. Las dos primeras sesiones presentan una estructura similar: } \\
\text { postura corporal, cualidades positivas, imágenes naturales, agradables y } \\
\text { expansivas. En la segunda sesión es capaz de introducir un elemento } \\
\text { nuevo: movimiento corporal. En la tercera sesión se consolidan los } \\
\text { contenidos anteriores y agrega capacidad de análisis existencial positivo. } \\
\text { Se pone de manifiesto en la paciente una capacidad de evolución positiva, } \\
\text { a lo largo de las tres sesiones, a merced del aprendizaje en la escucha } \\
\text { musical. }\end{array}$ \\
\hline
\end{tabular}

Tabla 7. Respuestas sobre el contexto relacional

Participante $\mathbf{n}^{\mathbf{0}} \mathbf{1}$

(1 $\left.{ }^{a}\right)$ Las hice solo. Un día estaba acompañado por mis hijas, en la habitación; ellas dormían. Es mejor estar solo, para estar con mis propios sentimientos. A veces me emociono. Si estás solo, no te ven llorar; a veces cerraba los ojos, para no distraerme con nada.

\section{$\left(2^{\mathrm{a}}\right)$ Es mejor estar solo.}

Participante n. $^{\circ} 2$

$\left(1^{a}\right)$ Lo hice sola, en mi habitación. Me retiraba dejando a los demás; les decía "voy a hacer eso", pero no comenté con ellos lo que hacía.

(2 $2^{\mathrm{a}}$ A mí me fue bien estar sola, es mejor así. Tal vez, si se hiciera en grupo, sería interesante, para comentar la experiencia.

Participante n. ${ }^{\circ} 3$

(1 $\left.{ }^{\mathrm{a}}\right)$ Lo hice sola. Preferí escribirlo y mi marido me ayudó a transcribir en limpio. Nada más. Los tuyos te ayudan con la enfermedad, pero hay un dolor interno que debes superar solo. Yo ya lo sabía, porque durante las sesiones de quimioterapia me llevaba música para escuchar por los auriculares en la sala de espera, y me ayudaba.

$\left(2^{a}\right)$ Prefería hacerlo sola, me relajaba, y me ayudaba, a veces casi me dormía... pero sola.

Finalmente, se resumen las respuestas sobre el contexto relacional, a las preguntas: 1) ¿Hizo las actividades acompañado/a por alguna otra persona?, ¿quién?, ¿en qué o cómo le ayudó? y 2) ¿Recomendaría que otras personas las realizaran acompañadas por alguien?, ¿por qué? (tabla 7), en las que los participantes expresaron y agradecieron tanto escuchar la música solos como sentir la cercanía de los familiares, y un participante manifestó interés por la posibilidad de que la tarea se pudiera haber realizado de manera grupal.

\section{Discusión}

La comparación de las variables de ansiedad y depresión (HADS) antes y después de cada sesión no indica presencia de patología en los tres participantes, y se mantiene la estabilidad emocional. Se reduce la ansiedad después de cada sesión y mejora el funcionamiento emocional. Hay una mejoría emocional global. En cuanto a la variación de los estados, disminuye la ansiedad y aumenta la depresión, los participantes consiguen un buen estado de relajación e intensifican la competencia de razonamiento. Esto es, aumenta su función intelectual, posiblemente porque reflexionan acerca de la propia enfermedad. La escala HADS ha sido útil para detectar diferentes niveles de respuesta emocional y de conducta de ansiedad y depresión, así como cualquier posible disfunción emocional durante la intervención (Lobo et al., 2002; López-Roig et al., 2000).

La comparación de las variables de estado de ánimo (EVEA) antes y después de cada sesión, a partir de los resultados de los cuatro estados emocionales de carácter situacional (tristeza-depresión, ansiedad, ira-hostilidad y alegría), manifiesta que en el estado ansiedad disminuyen los niveles-componentes de nerviosismo, tensión, ansiedad e intranquilidad, por lo tanto, se reduce la tendencia emocional negativa; los de irahostilidad y tristeza-depresión puntúan menos o se mantienen estables en algunos de los componentes; y los de alegría se mantienen estables en algunos de los suyos. En el análisis individual, el participante n. ${ }^{\circ} 2$, que presentaba ansiedad al inicio de la tercera sesión, al final de esta evolucionó hacia un mayor malestar, 
con valores más altos (no clínicos) en los distintos niveles-componentes, mientras que en ira-hostilidad y tristeza-depresión el puntaje se mantuvo y en alegría se elevó, lo que indica un buen funcionamiento emocional en estos últimos y un aumento puntual de la ansiedad en un momento dado de aquella sesión. La escala EVEA, según los objetivos del estudio, ha permitido evaluar los estados de ánimo transitorios en la escucha de música relajante en cada sesión (Sanz, 2001).

La comparación de las respuestas del estado de relajación (Berbel \& Casellas, 2018) antes y después de la intervención, evidencia mayor relajación de los tres participantes al final de cada sesión, con mejora en las respuestas de las preguntas: ¿ahora está o se siente preocupado?, ¿en estos momentos tiene o siente miedo?, ¿se siente excitado, nervioso o tenso?, aunque el participante $n .{ }^{\circ} 2$, al final de la tercera sesión, expresó más miedo. Los resultados totales muestran mejoría global de la relajación y sugieren que con la aplicación del modelo MCR mejora este estado al final de las tres sesiones.

Los resultados sugieren que escuchar música de carácter relajante según el modelo MCR puede reducir el estrés y la ansiedad, aunque se requerirán más estudios adicionales para validar dicho protocolo según los objetivos descritos.

Los estudios previos sobre los efectos de la música y la musicoterapia en el estrés y la relajación, con diseños muy heterogéneos, presentan resultados diversos (Umbrello et al., 2019). Elliot et al. (2014) sugieren que escuchar música relajante para el control de la ansiedad en el estado competitivo no parece más eficaz que escuchar música no relajante, pero la mejoría de las constantes fisiológicas sí justifica el uso de música relajante para mejorar la ansiedad. Linnemann et al. (2015) revelaron que la simple escucha de música fue eficaz para reducir los niveles de estrés subjetivo, pues los niveles de estrés subjetivo disminuyeron cuando se indicó la "relajación" como objetivo para escuchar música. Pero también los marcadores fisiológicos del estrés (niveles de cortisol) variaron en función del tipo de música seleccionada y se observó que con música energizante aumentaban y con música relajante disminuían.

En las respuestas sobre expectativas y beneficios del programa de musicoterapia (Berbel \& Casellas, 2018) al finalizar las tres sesiones, los tres participantes coinciden en su grado de satisfacción. El participante $n^{\circ} 2$ puntúa un nivel medio de 5 sobre 10 . Con todo, en la entrevista final, al igual que en los otros dos participantes, manifestó satisfacción general por la práctica realizada y por haber realizado las tres sesiones de manera individual, sin contacto con el entorno, pero mostró interés por haber realizado la actividad en grupo y compartir la experiencia. Deducimos que algunas personas, en función de su personalidad, aprovecharían mejor la intervención si fuera compartida, ya fuera como actividad grupal presencial o en telemedicina realizada en grupo. Ahora bien, todos valoran satisfactoriamente haber elegido hacer las escuchas individual- mente. Del mismo modo, las músicas propuestas en cada MCR personalizado son valoradas positivamente, y consideran que han sido bien programadas al ayudar a interiorizar y relajar.

Sobre la valoración del contexto relacional, los pacientes agradecen tanto escuchar la música solos como sentir la cercanía de los familiares, que podrían constituir un vínculo terapéutico. La alianza terapéutica, tratándose de personas sin trastorno psicológico que desarrollan su potencial de superación a través de ese trabajo de escucha musical, se deposita en los allegados con quienes tienen un vínculo afectivo positivo. Hay que explorar en los tipos de personalidad que podrían beneficiarse mejor de la práctica individual autónoma (telemedicina), o de la práctica grupal, en un contexto presencial.

Las categorías de representación cognitiva evidencian capacidades positivas en los siguientes aspectos: experimentación de sensaciones y emociones, desarrollo cognitivo, ideación de contenidos, lugares, personas que aportan sensaciones íntimas saludables, identificación interior, narraciones que manifiestan actitudes existenciales profundas... Coinciden en expresar emociones positivas $y$, cuando expresan las negativas (miedo, oscuridad), identifican rápidamente recursos cognitivos para superarlas. Expresan cualidades internas: expansión, simplicidad, amplitud, bondad, superación y esperanza. No hay mención de cualidades negativas. Destaca la manifestación de actitudes existenciales como referencias a la propia biografía, con alusiones a la enfermedad y a los tratamientos sufridos, haciendo énfasis en las expectativas de futuro, que tratan los modelos de psicoterapia existencial y también de la psicología positiva. Este modelo las incluye en la virtud "sabiduría y conocimiento" (Seligman, 2003). También en la fortaleza "vitalidad", que pertenece a la virtud "coraje", que es frecuente hallar en pacientes que han debido afrontar situaciones dolorosas. Estamos en una dimensión de resiliencia e hipotetizamos que es potente la escucha musical debidamente dirigida, en personas con esas virtudes. Finalmente, se manifiesta la fortaleza "amor" (la música estimula sentimientos nobles) y la virtud de "trascendencia", con sus fortalezas de apreciación de la belleza, gratitud, esperanza y optimismo, y espiritualidad. La música está conectada a todas ellas. Con escasas diferencias, causadas probablemente por características de la personalidad, la escucha ha ayudado a los participantes a crear un clima agradable, beneficioso para la mejora del estado de relajación, y reducir el malestar emocional.

Según los resultados y teniendo en cuenta que la música relajante actúa sobre la mejora de la relajación subjetiva y sobre parámetros fisiológicos (Elliot et al., 2014; Linnemann et al., 2015; Umbrello et al., 2019) esta puede ser adecuada para estos pacientes en seguimiento de atención oncológica. Sin olvidar que en la escucha de música con finalidad terapéutica se incluyen las preferencias musicales individuales y las que desde el saber neurocientífico, clínico y musical del musicoterapeuta, se consideran que permiten abordar con más 
eficacia la sesión y dar respuesta a las necesidades o los síntomas del paciente (Raglio, 2020).

La aplicación del modelo MCR por telemedicina ha sido satisfactoria. Como se recogió en el cuestionario inicial, los participantes ya tenían un buen vínculo con la música, y lo consolidaron con la escucha de música de carácter relajante. Basándonos en este también establecieron un buen vínculo con su propio self. La música relajante fomentó una relación positiva con uno mismo y les infundió optimismo y superación, y no pesimismo y depresión. Vemos, pues, que el protocolo MCR puede ser útil en pacientes que no manifiestan trastornos mentales, como oportunidad para la terapia de escucha musical. Según la teoría de Henry et al. (2016), vemos que se potencian las conductas preintencionales: las actitudes, las competencias y la conciencia, la capacidad de autocontrol y reflexión sobre uno mismo y se fortalecen aspectos positivos de la vida.

La aplicación por telemedicina se ha hecho en contextos íntimos, confortables. Los familiares han respetado la privacidad del practicante. Analizando sus contextos psicosociales vemos que su entorno familiar les facilita estabilidad emocional y tienen un estilo de vida basado en valores que garantizan un sentido vital positivo.

La relación sincrónica entre paciente y profesional de la salud, tal como la planea Glover (2020), ha quedado relegada. El soporte tecnológico ha permitido al paciente ganar autonomía, restando dependencia de los otros, y en todos los casos el contexto familiar ha aportado seguridad. La aplicación del protocolo MCR requiere un ambiente físico y psicológico que garantice la tranquilidad y también perfeccionar el seguimiento o el acompañamiento del profesional que, como apunta Raglio (2020), facilitará que la escucha de música pueda redefinirse periódicamente a través de entrevistas o de la administración de escalas de evaluación específicas si se considera necesario.

Queda pendiente explorar el funcionamiento de la alianza terapéutica entre el paciente y los profesionales. Sugerimos profundizar en la aplicación en línea del modelo de actitudes del terapeuta (Rogers, 1961) y analizar la relación aplicando el modelo de relación de ayuda, según las etapas y las habilidades específicas del terapeuta en cada etapa (Carkhuff, 2014; Egan, 1976), para identificar los factores más favorables del contexto y del ambiente relacional que aquí se han hecho evidentes. En el contexto se incluirían las variables que facilitan la escucha musical, además de las músicas, y otras como el lugar, los materiales o el clima relacional, al tratarse de una intervención familiar domiciliaria. Esas variables podrían ser relevantes en una intervención por telemedicina, asíncrona, tal como la hemos planteado en el estudio, sin seguimiento sincrónico del profesional.

Aunque por criterio de inclusión, las personas que han realizado la práctica gozaban de un estado de salud mental óptimo y no sufrían problemas emocionales diagnosticados como consecuencia de la enfermedad física, de las respuestas de un participante se deduce el interés por incluir un estudio de la personalidad en los futuros participantes.

\section{Limitaciones del estudio}

La principal limitación del estudio ha sido el tamaño de muestra, si bien ha consistido en un estudio clínico no empírico. La característica en línea de la intervención y de la evaluación ha impedido explorar variables que podrían ser significativas, como los cambios en los estados emocionales de los pacientes durante las sesiones. En posteriores aplicaciones del protocolo MCR por telemedicina, esta limitación debe tenerse en cuenta.

Hay evidencias de la importancia de las variables del contexto. En el futuro deben compararse los efectos del protocolo entre grupos domiciliarios (en línea) y grupos institucionales (hospitales de atención primaria). También puede trasladarse el método a contextos no familiares ni hospitalarios, como residencias sociosanitarias, con la colaboración interdisciplinaria de una red de profesionales más diversos. Será interesante interseccionar la investigación entre el ámbito oncológico y del envejecimiento saludable (residencial-sociosanitario), así como aplicar o evaluar el modelo más allá de la crisis sanitaria, aplicándolo cuando los pacientes realizan actividades habituales en su vida cotidiana, para constatar las mejoras en su calidad de vida.

A partir de algunos de los datos obtenidos se aconseja incluir en los estudios aspectos relacionados con la dimensión espiritual de la persona, su concepción del sentido de la vida, cómo influye en la percepción de su enfermedad y cómo la música puede favorecer esa reflexión. Se pueden integrar aspectos aportados por la logoterapia, una modalidad de psicoterapia existencial que funciona de manera complementaria a otros métodos terapéuticos o, en palabras de su creador, como "terapia inespecífica" (Frankl, 1987).

El estudio piloto ha permitido comprobar los efectos clínicos de este método de aplicación MCR en las respuestas emocionales en pacientes en seguimiento de atención oncológica, y ha puesto de manifiesto que la escucha de música de carácter relajante tiene efectos positivos en la mejora de la relajación y del estado emocional, y que puede resultar eficaz para aliviar la ansiedad y el estrés en pacientes de las mismas características. Realizar un estudio empírico servirá para comprobar los resultados.

\section{Recomendaciones}

Los resultados del estudio piloto muestran aspectos para ser tenidos en cuenta en la elaboración definitiva del protocolo aplicado en el ámbito hospitalario. La intervención ha incorporado características de la escucha musical y sus preferencias musicales, aspectos personales y específicamente emocionales de los participantes, haciendo un seguimiento de sus respuestas durante las sesiones, tal como sugieren Bradt et al. $(2015$; 2016). A partir de estos se sugiere: a) incluir un 
protocolo consensuado por el equipo de musicoterapia y clínico (oncólogo, psiconcólogo, enfermería) dirigido a evaluar las características de la personalidad de los pacientes participantes para anticipar necesidades de atención especial, así como dar apoyo o respuesta adecuada al paciente durante la actividad de escucha musical por el profesional implicado directo (enfermería) (Berbel \& Casellas, 2018); b) que la lista de reproducción de MCR de cada paciente pueda incluir nuevas músicas en cada sesión, que respondan a los gustos musicales individuales, para favorecer la relajación; y c) que con las diferentes listas de reproducción creadas a lo largo de las diferentes intervenciones o sesiones, el paciente pueda tomar conciencia de su finalidad como instrumento para la relajación y utilizarlo en cualquier momento de la vida diaria para la mejora de su bienestar y calidad de vida.

El método de aplicación MCR como tal puede ser aplicado en un contexto sanitario, pero la aplicación por telemedicina ha sido novedosa. Se han obtenido buenos resultados sobre el funcionamiento cognitivo y emocional de los pacientes, específicamente en cuanto a la estimulación de capacidades (fortalezas positivas) y la satisfacción general con la experiencia. También se ha comprobado cómo funciona una tarea de escucha musical en contexto domiciliario, las condiciones ambientales de intimidad y el papel del acompañamiento familiar. Las condiciones técnicas no han presentado dificultades. Queda pendiente explorar el funcionamiento de la alianza terapéutica entre el paciente y los profesionales (musicoterapeuta y, en este caso, psicólogo clínico). En este punto, se puede afirmar que la aplicación del método MCR por telemedicina ofrece muchas posibilidades como método terapéutico y es capaz de obtener beneficios psicológicos en el estado de ánimo y relajación.

Un último objetivo era explorar la aplicación del método, ya sea presencialmente o por telemedicina, con las oportunas adaptaciones, a otros perfiles de pacientes en el ámbito de la salud. Los resultados clínicos obtenidos hacen prever su interés para abrir una línea de intervención con pacientes de perfil semejante, independientemente del tipo de enfermedad.

\section{Declaración de divulgación de los autores: No} existen intereses en conflicto

\section{Referencias}

Aalbers, S., Fusar-Poli, L., Freeman, R. E., Spreen, M., Ket, J. C., Vink, A. C., Maratos, A., Crawford, M., Chen, X. J., \& Gold. C. (2017). Music Therapy for depression. Cochrane Database of Systematic Reviews, 11(11). https://doi.org/10.1002/14651858. CD004517.pub3

American Music Therapy Association (AMTA). (2019). Definition and Quotes about Music Therapy. http:// www.musictherapy.org/about/quotes/

Andreu, J. (2000). Las técnicas de análisis de contenido: Una revisión actualizada. Fundación Centro Estudios
Andaluces - Universidad de Granada, 10(2), 1-34. http:// mastor.cl/blog/wp-content/uploads/2018/02/ Andreu.-analisis-de-contenido.-34-pags-pdf.pdf. doi: 10.1002/14651858.CD004517.pub3

Arranz, P., Barbero, J. J., Barreto, P., \& Bayés, R. (2003). Intervención emocional en cuidados paliativos. Modelo y protocolos. Editorial Ariel Ciencias Médicas.

Bardin, L. (2002). El análisis de contenido. Ediciones AkalBerbel Sánchez, P. (2015). La eficacia de la terapia musical vs Diacepam para disminuir la ansiedad preoperatoria. [Tesis Doctoral, Facultat de Medicina Universitat Autònoma de Barcelona]. https://ddd. uab.cat/pub/tesis/2015/hdl_10803_309440/pbs1de1. pdf

Berbel, P., \& Casellas, M. (2018). Projecte Hospital Musical: Música i Teràpia musical. Comité Ético de Investigación con Medicamentos de Fundación Asistencial Mutua Terrassa (31 de octubre de 2018, acta 09/2018). No publicado.

Bradt, J., Potvin, N., Kesslick, A., Shim, M., Radl, D., Schriver, E., Gracely, E. J., \& Komarnicky-Kocher, L. T. (2015). The impact of music therapy versus music medicine on psychological outcomes and pain in cancer patients: A mixed methods study. Support Care Cancer, 23(5),1261-1271. https://doi.org/10.1007/ s00520-014-2478-7

Bradt, J., Dileo, C., Magill, L., \& Teague, A. (2016). Music interventions for improving psychological and physical outcomes in cancer patients. Cochrane Database of Systematic Reviews, 15(8). https://doi. org/10.1002/14651858.CD006911.pub3

Bradt, J. (2020). Impact of COVID-19 on Clinical Research. Nordic Journal of Music Therapy, 29(4), 297-299. https://doi.org/10.1080/08098131.2020.1777785

Bro, M. L., Jespersen, K. V., Hansen, J. B., Vuust, P., Abildgaard, N., Gram. J., \& Johansen, C. (2018). Kind of blue: A systematic review and meta-analysis of music interventions in cancer treatment. Psychooncology, 27(2), 386-400. https://doi.org/10.1002/ pon. 4470

Bruscia, K. E. (1999). Fundamentos de la Musicoterapia de Improvisación En: Modelos de Improvisación en Musicoterapia, (2 ed., pp. 7-21). Amaru Ediciones.

Cabrera, V., Martín-Aragón, M., Terol, M. C., Núñez, R., \& Pastor, M. Á. (2015). La Escala de Ansiedad y Depresión Hospitalaria (HAD) en fibromialgia: Análisis de sensibilidad y especificidad. Terapia Psicológica, 33(3),181-193. http://dx.doi.org/10.4067/S071848082015000300003

Carkhuff, R. (2014). Human Generativity, Vol I: The Scientific Legacy. HRD Press.

Chanda, M. L., \& Levitin, D. J. (2013). The neurochemistry of music. Review. Trends in Cognitive Sciences, 17(4), 179-193. https://doi.org/10.1016/j. tics.2013.02.007

Comisión Nacional para la protección de los sujetos humanos de investigación biomédica y del comportamiento. Informe Belmont. Principios y guías éticas para la protección de los sujetos humanos de investigación. 18 abril 1979. EE.UU. 
Corbella, S. \& Botella, L. (2003). La alianza terapéutica: Historia, investigación y evaluación. Revista Anales de Psicología, 19(2), 205-221. https://revistas.um.es/ analesps/article/view/27671

Corbella, S. (2019). El Estilo Personal del Terapeuta y la Alianza Terapéutica. En: H. Fernández-Álvarez y F. García (Eds.), El Estilo Personal del Terapeuta (pp. 57 90). Editorial Polemos.

Corbella, S. (2020). El psicoterapeuta en el proceso terapéutico. Revista de Psicoterapia, 31(116). https:// doi.org/10.33898/rdp.v31i116.409

Egan, G. (1976). Laboratorio de relaciones interpersonales. Editorial Paidós.

Elliott, D., Polman, R., \& Taylor, J. (2014). The effects of relaxing music for anxiety control on competitive sport anxiety. European Journal of Sport Science, 14 (1), 296-301. https://doi.org/10.1080/17461391.2012.6 93952

Frankl, V. E. (1987). Teoría y terapia de las neurosis. Editorial Herder.

Giordano, F., Zanchi, B., De Leonardis, F., Rutigliano, C., Esposito, F., Brienza, N., \& Santoro, N. (2020). The influence of music therapy on preoperative anxiety in pediatric oncology patients undergoing invasive procedures. The Arts in Psycotherapy, 68 (101649) https://doi.org/10.1016/j.aip.2020.101649.

Glover, K. K. (2020). A phenomenological study of the therapeutic relationship in tele- music therapy in the US. [Thesis de Master, Molloy College, Rockville Centre, NY.]. https://digitalcommons.molloy.edu/etd/85

Grocke, D., \& Wigram, T. (2011). Dos modos diferentes para analizar la música improvisada y hacer un informe sobre ella. En: Métodos receptivos en Musicoterapia: Técnicas y aplicaciones clínicas para musicoterapeutas, educadores y estudiantes (pp. 207-225). Amarú Ediciones.

Henry, B. W., Block, D. E., Ciesla, J. R., McGowan, B. A., \& Vozenilek, J. A. (2016). Clinician behaviors in telehealth care delivery: A systematic review. Advances in Health Sciences Education, 22, 869-888. http:// dx.doi.org/10.1007/s10459-016- 9717-2

Hernández, M., Cruzado, J. A., Prado, C., Rodríguez, E., Hernández, C., González, M. A., \& Martín, J. C. (2012). Salud mental y malestar emocional en pacientes con cáncer. Psicooncología, 9(2-3), 233-257. https://doi.org/10.5209/rev_PSIC.2013.v9.n23.40895

Jauset Berrocal, J.A. (2013). Cerebro y música, una pareja saludable. Las claves de la neurociencia musical. Editorial Círculo Rojo.

Jodelet, D. (1984). La representación social: Fenómenos, concepto y teoría. En: Moscovici, S., Psicología Social (pp. 469-493). Editorial Paidós.

Kamioka, H., Tsutani, K., Yamada, M., Park, H., Okuizumi, H., Tsuruoka, K., Honda, T., Okada, S., Park, S. J., Kitayuguchi, J., Abe, T., Handa, S., Oshio, T., \& Mutoh, Y. (2014). Effectiveness of music therapy: A summary of systematic reviews based on randomized controlled trials of music interventions. Patient Preference and
Adherence, 8, 727-754. https://doi.org/10.2147/PPA. S61340

Koelsch, S. (2009). A neuroscientific perspective on music therapy. Annals of the New York Academy of Sciences, 1169(1), 374-384. https://doi. org/10.1111/j.1749- 6632.2009.04592.x

Koelsch, S. (2018). Investigating the neural encoding of emotion with music. Neuron, 98(6), 1075-1079. https://doi.org/10.1016/j.neuron.2018.04.029

Lee, J. H. (2016). The effects of music on pain: A metaanalysis. Journal of Music Therapy, 53(4), 430-477. https://doi.org/10.1093/jmt/thw012

Lin, S. T., Yang, P., Lai, C.Y., Su. Y. Y., Yeh, Y. C., Huang. M. F., \& Chen, C. C. (2011). Mental health implications of music: Insight from neuroscientific and clinical studies. Harvard Review of Psychiatry, 19(1),3446. doi:10.3109/10673229.2011.549769

Linnemann, A., Ditzen, B., Strahler. J., Doerr, J. M., \& Nater, U. M. (2015). Music listening as a means of stress reduction in daily life. Psychoneuroendocrinology, 60, 82-90. https://doi.org/10.1016/j.psyneuen.2015.06.008

Lobo, A., Chamorro, L., Luque, A., Dal-Ré, R., Badia, X., \& Baró, E. (2002). Grupo de Validación en Español de Escalas Psicométricas (GVEEP). Validación de las versiones en español de la Montgomery-Asberg Depression Rating Scale y la Hamilton Anxiety Rating Scale para la evaluación de la depresión y de la ansiedad [Validation of the Spanish versions of the Montgomery-Asberg depression and Hamilton anxiety rating scales]. Medicina Clínica, 118(13), 493 -499. https://doi.org/10.1016/S00257753(02)72429-9

López-Roig, S., Terol, M. C., Pastor, M. A., Massuti, B., Rodríguez-Marín, J., Leyda, J. I., Neipp, M. C., Aragón, M. M., \& Sitges, E. (2000). Ansiedad y Depresión. Validación de la escala HAD en pacientes oncológicos. Revista de Psicología y Salud, 2(12), 127-157. https://www.researchgate.net/publication/265205073

Martí-Augé, P. (2015). Efecto de la musicoterapia en el estado de ánimo y calidad de vida de los pacientes con cáncer. [Tesi Doctoral, Facultat de Psicologia, Ciències de l'Educació i de l'Esport Blanquerna, URL]. http://hdl.handle.net/10803/359398

Marti-Augé, P., Mercadal Brotons, M., \& Solé Resano, C. (2015a). La Musicoterapia en Oncología. Gaceta Mexicana de Oncología, 14(6), 346-52. https://doi. org/10.1016/j.gamo.2015.11.013

Martí-Augé, P., Mercadal-Brotons, M., \& Solé-Resano, C. (2015b). Efecto de la musicoterapia en el estado de ánimo y calidad de vida de un grupo de mujeres supervivientes de cáncer de mama. Psicooncología, 12(1),105-128. https://doi.org/10.5209/rev_ PSIC.2015.v12.n1.48907

Martí-Augé, P., Mercadal-Brotons, M., \& Solé-Resano, C. (2015c). Efecto de la musicoterapia en el estado de ánimo y calidad de vida de pacientes con cáncer colorectal. Psicooncología. 12(2-3), 259-282. https:// doi.org/10.5209/rev_PSIC.2015.v12.n2-3.51008 
Mofredj, A., Alaya, S., Tassaioust, K., Bahloul, H., \& Mrabet, A. (2016). Music therapy, a review of the potential therapeutic benefits for the critically ill. Journal of Critical Care, 35,195-199. https://doi. org/10.1016/j.jcrc.2016.05.021

Moscovici, S. (1984). Psicología Social (I y II). Editorial Paidós.

Nogueda Orozco, M. J., Pérez Terán, B., Barrientos Casarrubias, V., Robles García, R., \& Sierra Madero, J. G. (2013). Escala de Ansiedad y Depresión Hospitalaria (HADS): Validación en pacientes mexicanos con infección por VIH. Psicología Iberoamericana,21(2),29-37. https://www.redalyc.org/articulo. oa?id=1339/133930525004

Ooishi, Y., Mukai, H., Watanabe, K., Kawato, S., \& Kashino M. (2017). Increase in salivary oxytocin and decrease in salivary cortisol after listening to relaxing slow- tempo and exciting fast-tempo music. PLoS ONE, 12(12). https://doi.org/10.1371/journal. pone.0189075

Pino-Sedeño, T. del, Peñate, W., \& Bethencourt, J. M. (2010). La escala de valoración del estado de ánimo (EVEA): Análisis de la estructura factorial y de la capacidad para detectar cambios en estados de ánimo. Análisis y Modificación de Conducta, 36(153-154), 19-32. http://hdl.handle.net/10272/6066

Poch, S. (1999). Metodología en Musicoterapia. En: Compendio de Musicoterapia (1, 129- 195). Herder Editorial.

Pocino, M., Luna, G., Canelones, P., Mendoza, A., Romero, G., Palacios, L. E. \& Castés,

M. (2007). La relevancia de la intervención psicosocial en pacientes con cáncer de

mama. Psicooncología, 4(1), 59-73.

https://revistas.ucm.es/index.php/PSIC/article/view/ PSIC0707120059A

Raglio, A., Filippi, S., Bellandi, D., \& Stramba-Badiale, M. (2014). Global music approach to persons with dementia: Evidence and practice. Clinical Interventions in Aging, 6(9), 1669-1676. https://doi.org/10.2147/ CIA.S71388

Raglio, A., Attardo, L., Gontero, G., Rollino, S., Groppo, E., \& Granieri, E. (2015). Effects of music and music therapy on mood in neurological patients. World Journal Psychiatry, 5(1), 68-78. doi: 10.5498/wjp. v5.i1.68ç

Raglio, A. (2020). Therapeutic music listening as telehealth intervention. Complementary Therapies in Clinical Practice, 41,101245. https://doi.org/10.1016/j. ctcp.2020.101245

Raheem, O. A., Mirheydar, H. S., Lee, H. J., Patel, N. D., \& Godebu, E. (2015). Does listening to music during office-based flexible cystoscopy decrease anxiety in patients: A prospective randomized trial. Journal of Endourology, 29(7), 791-796. https://doi.org/10.1089/ end.2015.0029

Rogers, C.R. (1961). El proceso de convertirse en persona. Editorial Paidós.

Rossetti, A., Chadha, M., Torres, B. N., Lee, J. K., Hylton, D., Loewy, J. V., \& Harrison, L. B. (2017). The impact of music therapy on anxiety in cancer patients undergoing simulation for radiation therapy. International Journal of Radiation Oncology Biology Physics, 99(1), 103-110. https://doi.org/10.1016/j.ijrobp.2017.05.003

Salimpoor, V. N., Benovoy, M., Larcher, K., Dagher, A., \& Zatorre, R.J. (2011). Anatomically distinct dopamine release during anticipation and experience of peak emotion to music. Nature Neuroscience, 4,257262. https://doi.org/10.1038/nn.2726

Sanz, J. (2001). Un instrumento para evaluar la eficacia de los procedimientos de inducción de estado de ánimo: La "Escala de Valoración del Estado de Ánimo" (EVEA). Análisis y Modificación de Conducta, 27(111),71-110. https://www.researchgate.net/publication/39148549

Sanz, J., Gutiérrez, S., \& García-Vera, M. P. (2014). Propiedades psicométricas de la Escala de Valoración del Estado de Ánimo (EVEA): Una revisión. Ansiedad y Estrés, 20(1), 27-49. http://www.ansiedadyestres.org/ content/vol-20_1-pp-27-49- 2014

Seligman, M. (2003). La auténtica felicidad. Editorial Vergara.

Sucala, M., Schnur, J. B., Constantino, M. J., Miller, S. J., Brackman, E. H., \& Montgomery, G. H. (2012). The therapeutic relationship in e-therapy for mental health: A systematic review. Journal of Medical Internet Research, 14(4), 110. http://dx.doi.org/10.2196/jmir.2084

Tan, P., Lester, L. H., \& Lin, A. M. (2020). Music therapy treatments in an inpatient setting: A randomized pilot study. The Arts in Psychotherapy, 69,101660. https://doi.org/10.1016/j.aip.2020.101660

Tanaka, Y., \& Nogawa, H. (2015). Evaluating the effects of singing songs in ethnic music therapy for dementia patients with a novel near-infrared spectroscopy (Data Analysis Method). International Journal of Gerontology, 9(1), 7-14. https://doi.org/10.1016/j. ijge.2014.01.006

Terol-Cantero, M. C., Cabrera-Perona, V., \& MartínAragón, M. (2015). Revisión de estudios de la Escala de Ansiedad y Depresión Hospitalaria (HAD) en muestras españolas. Anales de Psicología,31(2),494-503. https://doi.org/10.6018/analesps.31.2.172701

Umbrello, M., Sorrenti, T., Mistraletti, G., Formenti, P., Chiumello, D., \& Terzoni, S. (2019). Music therapy reduces stress and anxiety in critically ill patients: A systematic review of randomized clinical trials. Minerva Anestesiologica. 85(8), 886-898. doi: 10.23736/ S0375-9393.19.13526-2. Epub 2019 Apr 3.

Upadhaya, S., Yu, J. X., Oliva, C., Hooton, M., Hodge, J., \& Hubbard-Lucey, V. M. (2020). Impact of COVID-19 on oncology clinical trials. Nature Review Drug Discoveries 9(16), 376-377. doi: 10.1038 / d41573020-00093-1

Van der Steen, J. T., van Soest-Poortvliet, M. C., van der Wouden, J. C.,Bruinsma, M. S., Scholten, J., \& Vink, A. C. (2017). Music-based Therapeutic interventions for people with dementia. Cochrane Database of Systematic Reviews, 5(5).https://doi.org/10.1002/14651858. CD003477.pub3 
Warth, M., Kessler, J., Koenig, J., Wormit, A. F., Hillecke, T. K., \& Bardenheuer, H. J. (2014). Music therapy to promote psychological and physiological relaxation in palliative care patients: Protocol of a randomized controlled trial. BMC Palliative Care, 13(1), 60. https://doi.org/10.1186/1472-684X-13-60

Xue, C., Li, T., Yin, S., Zhu, X., \& Tan, Y. (2018). The influence of induced mood on music preference. Cognitive Processing, 19(4),517-525. https://doi. org/10.1007/s10339-018-0872-7
Yélamos, C., \& Fernández, B. (2009). Necesidades emocionales en el paciente con cáncer. En: W. Astudillo, E. Montiano, A. Salinas-Martín, E. Díaz-Albo, y C. Mendinueta (Eds.), Manejo del cáncer en atención primaria. (pp. 267-284). Sociedad Vasca de Cuidados Paliativos.

Zigmond, A. \& Snaith, R. (1983). The hospital anxiety and depression scale. Acta Psiquiátrica Escandinava, 67,361-370. https://doi.org/10.1111/j.1600-0447.1983. tb09716.x. 